\title{
A deterministic approach for the estimation of mutation rates in cultured mammalian cells
}

\author{
I-Chian $\mathrm{Li}^{1}$, Shu-Chen $\mathrm{Ho} \mathrm{Wu}^{2}$, Jiliang $\mathrm{Fu}^{1, *}$ and E.H.Y. Chu ${ }^{1, * *}$ \\ ${ }^{\prime}$ Department of Human Genetics, Medical School, and ${ }^{2}$ Department of Biostatistics, School of Public Health, University of Michigan, \\ Ann Arbor, MI 48109 (U.S.A.)
}

(Received 3 March 1984)

(Revision received 24 July 1984)

(Accepted 10 September 1984)

\section{Summary}

Unequal growth rates between mutant and wild-type cells in a large population constitute a problem for the estimation of mutation rate. Over a period of cell growth, a selective advantage of one cell type over the other might lead to considerable error in the estimation of mutation rate if equal growth rates are assumed. In this study, we propose a formula and apply it to the estimation of spontaneous mutation rate in a growing population of Chinese hamster V79 cells in which ouabain-resistant mutant cells exhibit a slower growth rate than the wild-type cells. The formula is a generalization of that previously presented by Armitage (1953), and this is the first attempt to apply the deterministic approach for mutation rate estimation to cultured mammalian cells. The value of the estimated rate is compared with that derived from a parallel experiment using the fluctuation test of Luria and Delbrück (1943). The limitations and advantages of taking the deterministic approach to mutation rate estimation in mammalian cell systems are discussed.

The rate of spontaneous mutation in cultured mammalian cell populations has generally been estimated by the fluctuation test of Luria and Delbrück (1943). The test is a stochastic or random approach, based on the distribution of the number of mutant colonies in a series of parallel cultures (Lea and Coulson, 1949).

Another approach for estimating mutation rate is the measurement of the increase of the 'mutant fraction' in a large cell population during a long

* Visiting Scholar (1981-83) from the School of Public Health, Sichuan Medical College, Chengdu, Sichuan, China.

** Send correspondence to: E.H.Y. Chu, Department of Human Genetics, Box 015, University of Michigan Medical School, Ann Arbor, MI 48109, U.S.A. (313) 764-1353. period of logarithmic growth. This is a deterministic approach, because the sizes of the normal and mutant cell populations at any time are determined exactly in terms of the growth rate, mutation rate, and the initial population size (Armitage, 1952, 1953). The method takes no account of the random nature of mutations, but gives a general trend of the result of mutational events. The method was originally designed for bacterial systems by Shapiro (1946), Newcombe (1948), and Stocker (1949). Armitage (1952, 1953) provides detailed statistical treatments of the procedure and gives formulae for the calculation of mutation rate.

In the estimation of mutation rate using either stochastic or deterministic approaches, it is usually 
assumed that the growth rates of wild-type and mutant cells are equal, even though this may not always be the case. For example, cultured fibroblasts from Bloom syndrome patients exhibit a slower growth rate than those from normal donors (Warren et al., 1981); abrin-resistant Chinese hamster ovary cells (Li et al., 1980) and thymidylatesynthetase-deficient Chinese hamster V79 cells ( $\mathrm{Li}$ and Chu, 1984) both grow at a slower rate than their respective wild-type parental cells. In a fluctuation test, a slower growth rate of mutant cells as compared to wild-type cells yields a smaller number of mutant colonies in each sib culture and a larger fraction of sib cultures containing no mutants. Hence, a revision of the rate estimation becomes necessary. Koch (1982) examines the effect of unequal growth rates of mutant and wildtype cells, and proposes formulae for the estimation of mutation rate using the fluctuation test. Using the deterministic approach, Armitage (1953) gives two general formulae (formulae 1 and 3 ) to determine the change of mutant fraction with time in a cell population. The formulae include both forward and backward mutation rates and the growth rates of normal and mutant cells. However, specific statistical treatments are proposed only for the case in which the growth rates are equal.

In the present study, Armitage's formulae are extended to establish the relationship between the change of mutant fraction with time. When there is an equal growth rate, the derived formula is simple and the relationship is linear. When the growth rates are unequal, the relationship is nonlinear and the formula becomes more complicated. For an experimental validation, the co-dominant ouabain resistance character (Baker et al., 1974) is used as a genetic marker. Changes of mutant fraction with time are monitored at intervals in a large population of Chinese hamster V79 cells maintaining in logarithmic growth. The growth of ouabain-resistant (oua ${ }^{r}$ ) mutant and the sensitive (oua ${ }^{\mathrm{S}}$ ) wild-type cells is determined either in separate cultures to obtain the absolute growth rate of each cell type, or in mixed cultures to obtain their relative growth rates. In both cases, oua ${ }^{r}$ cells are shown to grow slower than the oua ${ }^{S}$ cells. To our knowledge, the deterministic approach has not been applied previously to the estimation of mutation rates in cultured mammalian cells. Our study is the first experimental demonstration of mutation rate estimation by considering unequal growth rates of mutant and wild-type cells.

\section{Materials and methods}

\section{Cell culture}

Wild-type and ouabain-resistant V79 cells were grown in D10 medium, which is the modified Eagle's minimum essential medium, supplemented with $5 \%$ fetal calf serum (Gibco, Grand Island, New York, NY), $1 \mathrm{mM}$ sodium pyruvate, $50 \%$ increase in the normal levels of vitamins and essential amino acids and $100 \%$ increase in the level of non-essential amino acids. Cell cultures were maintained at $37^{\circ} \mathrm{C}$ in humidified air with $5 \%$ $\mathrm{CO}_{2}$.

\section{Fluctuation analysis}

23 parallel cultures were set up in D10 medium. The inoculum for each culture was $4.14 \times 10^{3}$ cells (corrected for plating efficiency), which were propagated to a final cell population of $1.56 \times 10^{7}$ cells (Fu et al., 1982; Li et al., 1983). All the cells in each culture were used for the experiment. $5 \times 10^{5}$ cells were seeded to each $9-\mathrm{cm}$ culture dish containing medium with $5 \times 10^{-4} \mathrm{M}$ ouabain. The selective medium was renewed on day 4 and resistant colonies were stained and counted on day 12.

\section{Mutant fraction analysis}

A large population (approximately $2 \times 10^{8}$ cells) of V79 cells were maintained in logarithmic growth in D10 medium in several culture flasks by frequent subculturing and medium renewal. At intervals of $2-4$ days, a sample of about $1 \times 10^{8}$ cells was taken and redistributed at $5 \times 10^{5}$ cells per culture dish containing the ouabain medium. The selective medium was renewed on day 4 and mutant colonies counted on day 12. After each sampling, a portion of the remaining population was maintained as a mass culture in D10 for subsequent samplings. 6 samplings were made at different times.

\section{Measurement of cell growth rate}

Replicate cultures of $5 \times 10^{4}$ cells per dish of either the wild-type cells or a mixture of equal 
numbers of cells from 10 different oua ${ }^{r}$ clones of independent origin were incubated at $37^{\circ} \mathrm{C}$. At 24-h intervals, cells from each dish were lysed with $2 \mathrm{ml}$ of $1 \mathrm{~N}$ sodium hydroxide solution and their optical densities of $260 \mathrm{~nm}$ were measured. This was converted to an equivalent cell number by the use of a pre-established standard curve.

Growth rates were determined according to the formula of $N_{\mathrm{t}}=N_{0} \cdot \mathrm{e}^{a t}$, where $N_{0}$ and $N_{\mathrm{t}}$ are the sizes of cell populations at time zero and $t$, and $a$ is the growth rate. A regression curve was constructed by plotting $\ln N_{\mathrm{t}}$ as the function of $t$; the slope of the regression curve was taken as the growth rate.

In a mutation experiment, since the wild-type and mutant cells are grown together, competition between the two cell types would mean that the relative growth cannot be measured in isolation. A more sensitive growth test was performed. A mixed culture was initiated which contained a ratio of $10^{4}$ oua $^{\mathrm{s}}$ cells to 1 oua $^{\mathrm{r}}$ cell. Oua ${ }^{\mathrm{r}}$ cells consisted of an equal mixture of 10 mutant clones of independent origin. The culture was kept in continuous logarithmic growth for 2 weeks by repeated subculturing. The population size was maintained at less than $10^{7}$ cells to reduce the possibility of introducing new spontaneous mutation into the population. The ratio of the two cell types was measured at intervals by taking an aliquot of the cultured cells and plating in selective or normal media. The regression relation between the ratio of the mutant to the wild-type cells and time was established. If the slope of regression line deviates significantly from zero, a loss of a proportion of mutant cells with time is assumed.

\section{Calculation of generation number}

Generation time, $T$, which is a measure of the length of time required for the population size to double, was measured according to the formula: $2 N=N \cdot \mathrm{e}^{a T}$. Hence, $T$ is equal to $(\ln 2) / a$. The time required for a cell population to grow from $N_{0}$ to $N_{\mathrm{t}}$ was also expressed in terms of generation time: $t=g \cdot T$, where $g$ is the number of generation (division) cycles (or simply generations) elapsed between time zero and time $t$. Therefore, $g$ is calculated as $\ln \left(N_{\mathrm{t}} / N_{0}\right) / \ln 2$.

\section{Calculation of mutation rates}

Throughout this paper, mutation rate $(\mu)$ is expressed as the number of mutations/cell/division cycle. When $\mu$ is estimated from the result of the fluctuation test, under the assumption of equal growth rates for both wild-type and mutant cells, Eqn. 4 of Luria and Delbrück is used with a multiplicative factor $\ln 2$ :

$\mu=m \cdot \ln 2 /\left(N_{\mathrm{t}}-N_{0}\right)$

where $m$ is the number of mutations in the cell population, and $N_{0}$ and $N_{\mathrm{t}}$ are, respectively, the initial and final cell numbers in the population. $m$ is calculated by equating the observed proportion of cultures with no mutant, $\hat{P}_{0}$, to $\mathrm{e}^{-m}$ (Eqn. 5 of Luria and Delbrück).

Koch (1982) proposes a modified formula for the situation in which two growth rates are not equal. We rearrange his formula and add a factor of $\ln 2$ so that the definition of $\mu$ matches ours:

$\mu=[\rho(1-v) \cdot \ln 2] / N_{\mathrm{s}}\left[1-\mathrm{e}^{-(1-v) s}\right]$

where $\rho$ is the mean number of mutants at time units $s ; s=t /(T / \ln 2)$, where $t$ is the clock time, $T$ is the generation time, and $v=b / a$. $a$ and $b$ are the growth rates of wild-type and mutant cells respectively.

To calculate $\mu$ from the mutant fraction method in the situation where two growth rates are not equal, we solve Eqn. 2 of Armitage (1953) and use the time unit $(T / \ln 2)$ of Luria and Delbrück (1943). Clock time $t$ was also transformed into time units $s$. Defining mutation rate $\lambda$, as mutations/cell/time unit, we solve the equation:

$\psi_{s}=1-\left[1+\frac{\lambda}{w}+\left(\psi_{0}-\frac{\lambda}{w}\right) \mathrm{e}^{-w s}\right]^{-1}$

where $\psi_{s}$ and $\psi_{0}$ are the mutant fractions at $s$ units of time and time zero respectively, $w$ is $(1-\lambda-$ $b / a), a$ and $b$ are the growth rates for wild-type and mutant cells respectively. The mutation rate, $\mu$, expressed as mutations/cell/division cycle, is then obtained by $\mu=\lambda \cdot \ln 2$. A non-linear regression analysis is performed for the estimations of $\lambda$ or $\mu$ by utilizing BMDP3R from the BMDP statistical package (Jennrich, 1983).

In the case of equal growth rates, Eqn. 1 is 
further simplified to become:

$$
\begin{aligned}
\psi_{\mathrm{g}} & \approx \psi_{0}+\lambda \cdot g \cdot \ln 2 \\
& \approx \psi_{0}+\mu \cdot g
\end{aligned}
$$

\section{Results}

Growth rates of wild-type and ouabain-resistant cells The average values of the growth rates obtained from the slopes $( \pm$ S.E.) of regression curves of $1 n$ $N_{\mathrm{t}}$ against $t$ were $0.048 \pm 0.0012 / \mathrm{h}$ and $0.043 \pm$ $0.0012 / \mathrm{h}$ for the oua ${ }^{\mathrm{s}}$ and oua ${ }^{\mathrm{r}} \mathrm{V} 79$ cells, respectively (Fig. 1); the difference between slopes is significant at $5 \%$ level $(P<0.02)$. These values are equivalent to a generation time, $T$, of $14.44 \mathrm{~h}$ for the oua ${ }^{\mathrm{s}}$ and $16.50 \mathrm{~h}$ for oua ${ }^{\mathrm{r}}$ cells.

In Fig. 2 a selective disadvantage is apparent for the slow-growing oua ${ }^{\mathrm{r}}$ cells in the mixed culture. There is a gradual reduction in the proportion of mutant cells, greater than could be expected from back mutation or sampling error. In fact, the linear relation between the percent of oua $^{r}$ recovered $(R)$ and the generation number $(g)$ obeys an empirical equation of $R=0.93-0.7 \% \mathrm{~g}$,

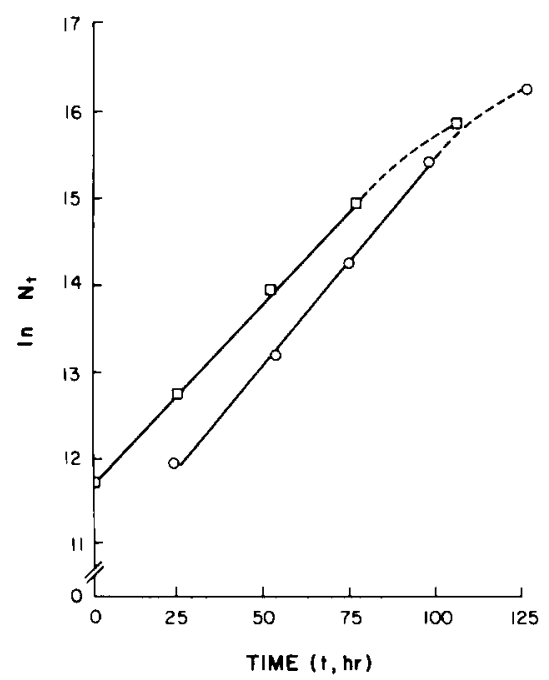

Fig. 1. Linear regression correlation between cell number (ln $N_{\mathrm{t}}$ ) and clock time $(t)$ in hours. The growth rates, taken from the slopes of linear regression lines (solid lines only), are $0.048 / \mathrm{h}$ and $0.043 / \mathrm{h}$, respectively, for the wild-type $(O)$ and oua $^{r}(\square)$ cells.

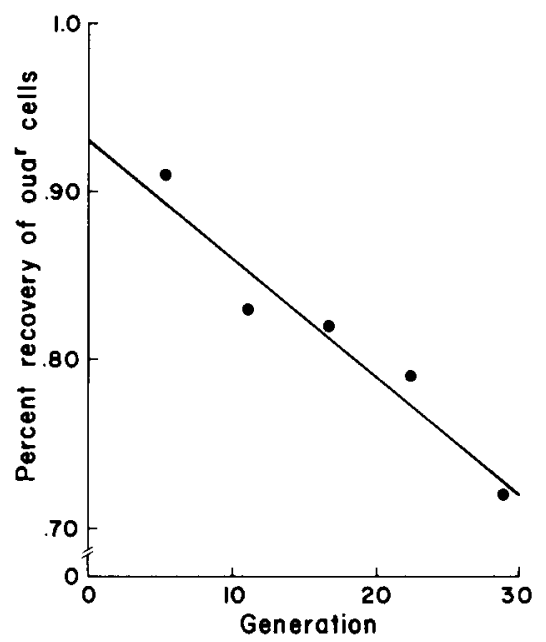

Fig. 2. Linear regression correlations between percent recovery $(R)$ of oua ${ }^{r}$ cells in a mixed culture of oua ${ }^{r}$ and oua ${ }^{\mathrm{s}}$ cells and the generation number. The curve obeys equation $R=0.93-$ $0.7 \% \mathrm{~g}$ and has a correlation coefficient of -0.95 .

\section{TABLE 1}

ESTIMATION BY FLUCTUATION ANALYSIS OF THE RATE OF MUTATIONS FROM OUABAIN SENSITIVITY TO RESISTANCE IN CHINESE HAMSTER V79 CELLS IN

\begin{tabular}{|c|c|}
\hline Number of cultures $(C)$ & 23 \\
\hline $\begin{array}{l}N_{0} \\
N_{\mathrm{t}}\end{array}$ & $\begin{array}{l}4.14 \times 10^{3} \\
1.56 \times 10^{7}\end{array}$ \\
\hline $\begin{array}{l}\text { Mutant colonies }(y) \\
\text { Total } \\
\text { Range } \\
\text { Mean }(\bar{y}) \\
\text { Variance }(\operatorname{var}(y)) \\
\operatorname{var}(y) / \bar{y}\end{array}$ & $\begin{array}{l}59 \\
0-45 \\
2.6 \\
82.2 \\
31.6\end{array}$ \\
\hline $\begin{array}{l}\hat{P}_{0}^{\mathrm{b}} \\
\hat{\mu}^{\mathrm{c}} \\
\hat{\mu}^{\mathrm{d}}\end{array}$ & $\begin{array}{c}11 / 23=0.48 \\
3.26 \times 10^{-8} \\
2.09 \times 10^{-8}\end{array}$ \\
\hline $\begin{array}{l}\text { The number of genera } \\
\text { was } 11.9 \text {. A total num } \\
11.81 \text { of medium were } \\
\text { b The observed fraction } \\
\text { colonies. } \\
\text { c Mutations/cell/divisic } \\
\text { correction for unequal } \\
\text { d } \text { Mutations/cell/divisi } \\
\text { mutant colony methoc } \\
\text { unequal growth rates. } \\
\times 10^{3}=3.77 \times 10^{3} \cdot \hat{\mu} \\
10^{7}\left[1-\left(3.77 \times 10^{3}\right)^{-(1}\right.\end{array}$ & $\begin{array}{l}\text { involved in this experiment } \\
6 \text { culture dishes }(9 \mathrm{~cm}) \text { and } \\
\text { he experiment. } \\
\text { ltures containing no mutant } \\
\text { calculated from } \hat{P}_{0} \text { with no } \\
\text { tes. } \\
\text { calculated from the mean } \\
\text { (1982) with a correction of } \\
=N_{0} \cdot \mathrm{e}^{s}, \mathrm{e}^{s}=1.56 \times 10^{7} / 4.14 \\
-0.043 / 0.048) \cdot \ln 2] / 1.56 \times \\
8)]=2.09 \times 10^{-8} \text {. }\end{array}$ \\
\hline
\end{tabular}
CULTURE $^{\text {a }}$ 
TABLE 2

THE INCREASE OF THE PROPORTION OF OUABAIN-RESISTANT (oua ${ }^{\mathrm{r}}$ ) CELLS IN A CHINESE HAMSTER V79 CELL POPULATION DURING LOGARITHMIC GROWTH IN VITRO ${ }^{a}$

\begin{tabular}{lllll}
\hline $\begin{array}{l}\text { Time } \\
\text { (days) }\end{array}$ & $\begin{array}{l}\text { Number of } \\
\text { generation } \\
\text { cycles }(g)\end{array}$ & $\begin{array}{l}\text { Number of cells } \\
\text { sampled } \\
\left(\times 10^{7}\right)\end{array}$ & $\begin{array}{l}\text { oua }^{\mathrm{r}} \\
\text { colonies } \\
\text { detected }\end{array}$ & $\begin{array}{l}\text { oua }^{\mathrm{r}} \\
\text { fraction }^{\mathrm{C}} \\
\left(\times 10^{-7}\right)\end{array}$ \\
\hline 0 & 0 & 7.07 & 3 & 0.43 \\
2 & 2.28 & 7.55 & 8 & 1.06 \\
4 & 8.26 & 8.32 & 10 & 1.20 \\
6 & 10.79 & 8.64 & 11 & 1.27 \\
8 & 14.02 & 7.91 & 16 & 2.02 \\
12 & 18.95 & 6.42 & 18 & 2.80 \\
\hline
\end{tabular}

a A total of 1200 culture dishes $(9 \mathrm{~cm})$ and $19.5 \mathrm{l}$ of medium were used for the experiment.

b Corrected for plating efficiency.

indicating that the fraction of oua ${ }^{r}$ cells decreased by a factor of $(0.7 \pm 0.1) \%$ per generation. This slope is significantly different from zero $(P=$ 0.008 ).

\section{Calculation of mutation rates}

Table 1 shows the results of a fluctuation analysis for the spontaneous occurrence of oua ${ }^{\mathrm{r}}$ mutants in V79 cell populations. The mutation rate, $\mu$, calculated from the $P_{0}$ method with no correction of unequal growth rate, is $3.26 \times 10^{-8}$ mutations/ cell/division cycle. Considering unequal growth rate and applying the mean mutant colony method of Koch (1982), we obtain the corrected mutation rate as $2.09 \times 10^{-8}$ mutations/cell/division cycle.

In Table 2, the increase of the proportion of oua $^{r}$ cells in a logarithmically growing V79 cell population is shown. Because the growth rates of mutant and wild-type cells appear to be unequal, the mutation rate is calculated from our Eqn. 1. The two empirical growth rates and the observed mutant fractions are put into Eqn. 1 to obtain a rate of $3.04 \times 10^{-8}$ mutations/cell/time unit. This value, multiplied by $\ln 2$, is equivalent to $2.11 \times$ $10^{-8}$ mutations/cell/division cycle.

\section{Discussion}

Mutation occurs as a random event during the growth of a cell population. Mutation rate is, therefore, a measure of the production of mutant cells as a function of time. Mutant cells divide in the presence of wild-type cells, but the rates of division for the two cell types may differ. Growth rate, hence, is a factor that must be taken into consideration in the estimation of mutation rate.

In the present study, ouabain-resistant mutant V79 cells are shown to grow slower than the wild-type parental cells, in either separate or mixed culture of the two cell types. Considering the unequal growth, we extend a formula from Armitage (1953) to estimate mutant fractions at any time point. For the purpose of illustration, we also simplify the formula of Armitage to yield a linear change of mutant fraction with time when the growth rates of the two cell types are the same.

In the course of a mutation experiment, the growth rate of the cell population as a whole changes due to interruptions for cell sampling and subculturing. It becomes necessary to measure time in terms of generation (division cycle) instead of clock time. "This is equivalent to giving a fixed value to the growth rate' (Armitage, 1953, p. 165). We accordingly use the fixed values of growth rate to calculate mutation rate. This rate is $2.11 \times 10^{-8}$ mutations/cell/division cycle, compared to 2.09 $\times 10^{-8}$ mutations/cell/division cycle derived from the fluctuation test by following the mean mutant colony method of Koch (1982). These two estimates are in good agreement, despite the differences in approaches and experimental methods.

In our experiment, the cell population was maintained at approximately $10^{8}$ cells. However, at the conclusion of the experiment, we realized that the cell populations even at this size were not large enough, because the reciprocal of mutation 
rate was in the order of $5 \times 10^{7}$. Fluctuation of mutant fractions with time due to sampling error was likely to occur. This may explain the observed uneven increment of mutant fraction with time.

There are still some unsolved fundamental problems concerning the estimation of mutation rates. Our understanding on the basic mechanisms of spontaneous mutagenesis is limited. We still do not know how to deal with the effect of differential plating efficiency on the mutation rate estimation. The present study is the first experimental attempt of mutation rate estimation when the growth rates of mutant and wild-type cells are unequal. We demonstrate the feasibility of applying the deterministic approach to the mutation rate estimation in a mammalian cell system. The study is just a beginning and there are numerous technical problems to overcome both in the design and execution of experiments. On the other hand, there are several advantages of the deterministic approach: First, the effect of phenotypic delay can usually be neglected (Armitage, 1953), as it merely shifts the regression curve to the right and will not affect the regression coefficient. Second, the method can be used to obtain a rough estimate of mutation rate if only two mutant fractions are measured at two time points, as it has been done with bacteria (Newcombe, 1948) or cultured mammalian cells (Warren et al., 1981; Liu et al., 1982). Third, by appropriate experimental design, more than one sample can be taken at any time point from a large and exponentially growing cell population. Each sample can be used for mutation rate estimation using different markers. Thus, more than one mutation rate can be estimated simultaneously. Finally, statistical methods are available for a comparison of mutation rates obtained from different cell lines. The comparison is based on the $t$ test on the regression coefficients of mutant fractions over time. Taken together, the mutant fraction method may be used to yield an independent estimate of spontaneous rates of somatic mutations other than by the fluctuation test.

\section{Acknowledgement}

This work was supported by a grant (CA 26803) from the U.S. Public Health Service.

\section{References}

Armitage, P. (1952) The statistical theory of bacterial populations subject to mutation, J. Roy. Statist. Soc. B, 14, 1-40.

Armitage, P. (1953) Statistical concepts in the theory of bacterial mutation, J. Hyg., 51, 162-184.

Baker, R.M., D.M. Brunette, R. Mankovitz, L.H. Thompson, G.F. Whitmore, L. Siminovitch and J.E. Hill (1974) Ouabain-resistant mutants of mouse and hamster cells in culture, Cell, 1, 9-12.

Fu, J., I.-C. Li and E.H.Y. Chu (1982) The parameters for quantitative analysis of mutation rates with cultured somatic cells, Mutation Res., 105, 363-370.

Jennrich, R. (1983) BMDP3R, nonlinear regression, In: W.J. Dixon (Ed.), BMDP Statistical Software, University of California Press, Los Angeles, CA pp. 290-303.

Koch, A.L. (1982) Mutation and growth rates from Luria-Delbrück fluctuation tests, Mutation Res., 95, 129-143.

Lea, D.A., and C.A. Coulson (1949) The distribution of the numbers of mutants in bacterial populations, J. Genet., 49, 264-285.

Li, I.-C., and E.H.Y. Chu (1984) Mutants of Chinese hamster cells deficient in thymidylate synthetase, J. Cell. Physiol., $120,109-116$.

Li, I.-C., D.A. Blake, I.J. Goodstein and E.H.Y. Chu (1980) Modification of cell membrane in variants of Chinese hamster cells resistant to abrin, Exp. Cell Res., 129, 351-360.

Li, I.-C., J. Fu, Y.-T. Hung and E.H.Y. Chu (1983) Estimations of mutation rates in cultured mammalian cells, Mutation Res., 111, 253-262.

Liu, P.K., C.-C. Chang and J.E. Trosko (1982) Association of mutator activity with UV sensitivity in an aphidicolin-resistant mutant of Chinese hamster V79 cells, Mutation Res., $106,317-332$.

Luria, S.E., and M. Delbrück (1943) Mutations of bacteria from virus sensitivity to virus resistance, Genetics, 28 , $491-511$.

Newcombe, H.B. (1948) Delayed phenotypic expression of spontaneous mutation in Escherichia coli, Genetics, 33, 447-476.

Shapiro, A. (1946) The kinetics of growth and mutation in bacteria, Cold Spring Harbor Symp. Quant. Biol., 11, 228-234.

Stocker, B.A.D. (1949) Measurement of rate of mutation of flagellar antigenic phage in Salmonella typhimurium, J. Hyg., $47,398-413$.

Warren, S.T., R.A. Schultz, C.C. Chang, M.H. Wade and J.E. Trosko (1981) Elevated spontaneous mutation rate in Bloom syndrome fibroblasts, Proc. Natl. Acad. Sci. (U.S.A.), 78, 3133-3137. 